\title{
The Impact of Sad-Spending on Emotional Recovery Process
}

\author{
Minghui He, Aimei Li \\ School of Management, Jinan University, Guangzhou, China \\ Email:miffy_he@qq.com
}

Received 10 December 2015; accepted 18 January 2016; published 21 January 2016

Copyright (C) 2016 by authors and Scientific Research Publishing Inc.

This work is licensed under the Creative Commons Attribution International License (CC BY). http://creativecommons.org/licenses/by/4.0/

(c) (i) Open Access

\begin{abstract}
Sad-spending is a typical kind of compensatory consumption. Some scholars found that consumers would spend more money when they were sad, which is called "sad-spending" effect. Both conscious and unconscious consumption would benefit the consumers, such as emotional recovery process. Based on former studies, we examine how the sad-spending would impact emotional recovery process and subjective well-being. The results show that sad-spending could improve consumers' positive emotions, while it's not sure that it could decrease negative emotions. Besides, sad-spending would improve consumers' satisfaction.
\end{abstract}

\section{Keywords}

Sad, Compensatory Consumption, Emotional Recovery, Subjective Well-Being

\section{Introduction}

What shall we do when we are sad, such as going shopping or chatting with friend? Since the modern pace of live has become faster and faster, it's more and more difficult for us to find someone have a chat. People have to choose the other way like shopping to relieve themselves. However, would this consuming behavior make people happier? We will try to examine this phenomenon through the following study.

Gronmo (1993) proposed that if $\mathrm{Y}$ is used to make up the lack of $\mathrm{X}$, the process is compensation behavior (Gronmo, 1988). After Woodruffe (1997) examined the shopping behavior, he proposed a definition called Compensation Consumption, which refers to the process when people feel request, lack or desire, they can't fix it in original way and then go shopping to satisfy themselves (Woodruffe, 1997). According to Rucker and Galinsky (2013), compensation means that somebody uses consumptions to remedy the threat of identity or reach an ideal psychological status consciously or unconsciously (Woodruffe, 1997). Some scholars define the compensation consumption as a substitute measure to satisfy their psychological needs (Zheng \& Peng, 2014). It's a consumption used to make up some psychological deficit or ego threat. This is a new field which was paid a lot 
attention to by the scholars in consuming behavior. But it's still a problem whether compensation consumption could recover consumers' emotions.

Many scholars proved that people would use retail therapy to fix their emotions. In other words, sadness would lead to more consumption. Sad people are willing to spend more money for one product. Through experiments, Lerner (2000) found that the sad participants would spent more money to buy one product (Lerner \& Keltner, 2000). Raghunathan et al. (1999) proved that sad people prefer hedonic consumption (Raghunathan \& Pham, 1999). Wansink et al. (2003) also found that sad people prefer consuming some comfortable food and drink, like ice-cream and pizza (Wansink, Cheney, \& Chan, 2003). Otherwise, Garg et al. (2007) discovered that, compared to happiness, sad people prefer to buy hedonic products like popcorn and button (Garg, Wansink, \& Inman, 2007). Manucia and Baumann (1984) proposed Mood Repair Theory, which considered that people would buy more things in order to reduce sadness (Manucia, Baumann, \& Cialdini, 1984). Raghunathan and Corfman (2004) constructed a model called different affect-different effect, emphasizing that different emotions lead to different effects (Raghunathan \& Corfman, 2004). For example, sadness would lead to hedonic consumption and anxiousness would lead to more attention to the details.

Under the emotion of sadness, consumers would loss control. As a willingness that wants to make things controllable, they start to consume more. This phenomenon was called sad-spending effect (Cryder, Lerner, \& Gross et al., 2008). Many studies only examined that sadness would lead to more consumption behavior, but rarely examined the impact of sad-spending on emotional recovery process. Atalay (2011) found that sad participants would consume more and their emotions were improved after compensation consumption (Atalay \& Meloy, 2011). Scott (2012) also discovered that, sad participants' emotions turned better after finishing consuming tasks. Li and Li (2013) made a summary of sad-spending effects (Li \& Li, 2011). Only few studies about compensation consumption could be found in China.

The present study paid much attention to the relationship between sadness and compensation consumption whether compensation consumption would improve emotion, which not only proved the impact of sad-spending on emotional recovery process, but also further examined whether sadness would lead to more consumption. It supplemented the area of compensation consumption and offered a good reference to consumers and enterprises. Consumers could strengthen their self control to be more rational during consuming. As a result, they can avoid economic loss and the bad impact which unhealthy emotions bring to them. The companies could make use of consumers' compensation consumption behavior to set out special promotion to gain more benefits. Besides, most analyses about compensation consumption were conducted in west countries. We decided to do this research in Chinese environment to examine how the different effects would happen in China.

\section{Study 1}

We designed our first study which conducted in laboratory to examine the impact of sad-spending on positive emotions and negative emotions.

\subsection{Method}

Participants. We recruited 30 participants (14 male and 16 female) attending pre-experiment and 130 participants joining formal study. After deleting valueless questionnaires, there are 128 valuable questionnaires (61 male and 67 female) for the formal study. The average age of participants is $22.74 \pm 2.75$.

Materials and procedure. Firstly, participants were first informed to read a sad scenario that describes how parents love them and get old. Then we let the participants to think what they have done for their parents and write down their feelings and choose a face expressional which conforms to their feelings (see Figure 1). After reading, participants were asked to finish positive and negative affect scale (PANAS). Then we recycled the scales and provided another questionnaire for participants. In this questionnaire, we assumed that each participant own 100 yuan and asked them to choose subjects they want to buy within 12 products (10 yuan for each product), including 6 hedonic products (chocolate, cookie, juice, gum, milk tea, toy) and 6 utilitarian products (note book, pen, flashlight, file bag, storage box, pencil box). Following that, they have to fulfill the PANAS again. At last, they wrote down some personal information like sex and age.

\subsection{Results}

Based on the pre-experiment data, the scenario prime participants' sadness effectively and the average sad level 


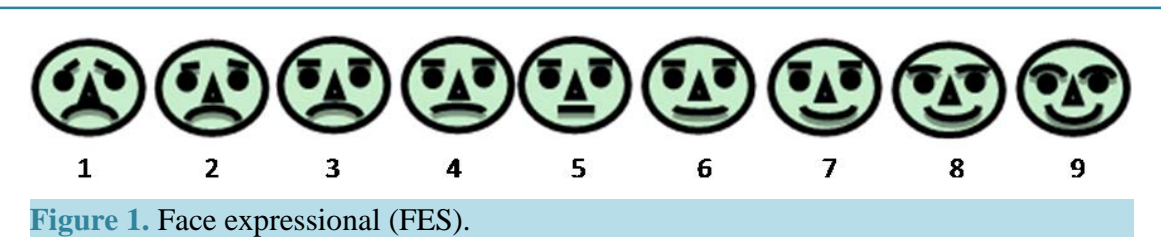

is $2.80 \pm 0.23$. Otherwise, backward positive emotions are higher than forward ones $(t=3.24, p<0.01)$ and the average of difference is $4.47 \pm 7.56$. Backward negative emotions are lower than forward ones $(t=-6.09, p<$ 0.001 ) and the average of difference is $-6.67 \pm 6.00$. It shows that after consumption, participants have less negative emotions and more positive emotions.

Then we analyzed the formal study's data. Firstly, we examined the reliability of PANAS. The Cronbach alpha coefficient of forward and backward positive emotions are $\alpha=0.88$ and $\alpha=0.93$. The Cronbach alpha coefficient of forward and backward negative emotions are $\alpha=0.88$ and $\alpha=0.92$.

Compared with forward data and backward data, backward positive emotions are higher than forward ones ( $t$ $=2.97, p<0.01)$ and the average of difference is $1.82 \pm 6.95$. Backward negative emotions are lower than forward ones $(t=-10.90, p<0.001)$ and the average of difference is $-5.34 \pm 5.54$. The changes of positive and negative emotions before and after compensation consumption are shown in Figure 2. The results show that after consumption, participants’ positive emotions were improved and negative emotions were decreased.

Besides, consumption sum, including hedonic consumption and utilitarian consumption, has a positive effect on positive emotions and it explains $4 \%$ of the difference. But it doesn't affect negative emotions. In other words, consumption makes sad participants feel more positively but there's no difference in their negative emotions. The regression results of consumption on the change of positive emotions and negative emotions are shown in Table 1.

Furthermore, negative emotions positively influenced participants' consumption sum and it explains 4\% of the difference. Negative emotions positively influenced participants’ hedonic consumption and it explains 5\% of the difference, while it doesn't have an effect on utilitarian consumption. It means that negative emotions would increase consumption, especially hedonic consumption. The regression results of consumption on consumption sum, hedonic consumption and utilitarian consumption are shown in Table 2.

We also tried to use ANOVA to examine whether sex has an influence on negative emotions and consumption. The results show that there's no difference between female and male participants.

\section{Study 2}

We designed our second study which conducted in laboratory to examine the impact of sad-spending on not only positive emotions and negative emotions but also satisfaction. We tried to examine the results of study 1 by different priming method.

\subsection{Method}

Participants. We recruited 30 participants (13 male and 17 female) attending joining this study. The average age of participants is $21.60 \pm 1.28$.

Materials and procedure. Firstly, participants were first informed to watch a sad video "when I sing this song" that describes an old man's memory of he and his wife from the time they met each other to his wife's death. Then we let the participants to think what they have done for their parents and write down their feelings and choose a face expressional which conforms to their feelings (same as Study 1). After that, participants were asked to finish PANAS and satisfaction scale including Satisfaction with Life Scale by Pavot and Diener (1993) and self anchoring scale by Kilpatrick and Cantril (1960). The rest procedure are the same as Study 1.

\subsection{Results}

Compared with forward data and backward data of emotions, backward positive emotions are higher than forward ones $(t=4.34, p<0.001)$ and the average of difference is $8.20 \pm 10.35$. Backward negative emotions are lower than forward ones $(t=-3.17, p<0.01)$ and the average of difference is $-6.20 \pm 10.73$. The changes of positive and negative emotions before and after compensation consumption are shown in Figure 3.

Compared with forward data and backward data of satisfaction, both backward satisfactions are higher than 
positive emotions

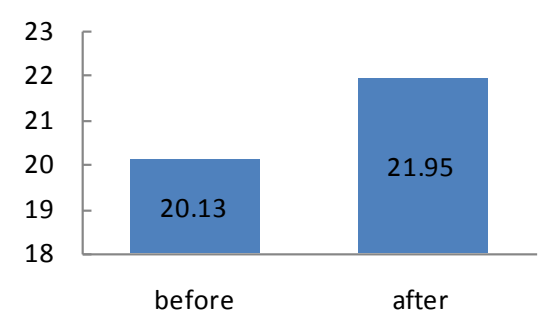

negative emotions

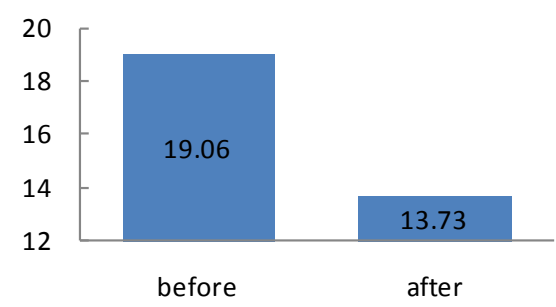

Figure 2. Changes of positive and negative emotions before and after compensation consumption (study 1).

\section{positive emotions}

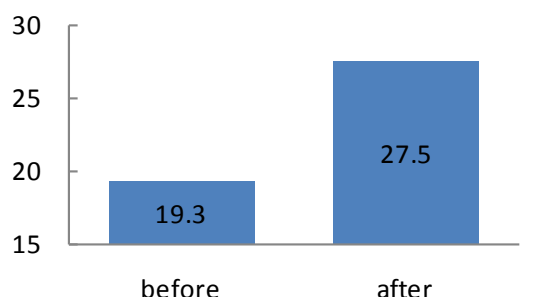

\section{negative emotions}

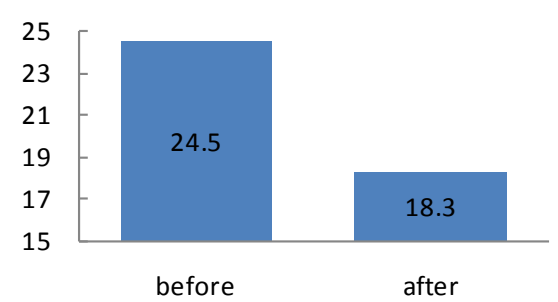

Figure 3. Changes of positive and negative emotions before and after compensation consumption (study 2).

Table 1. Regression results of consumption on the change of positive and negative emotions.

\begin{tabular}{|c|c|c|c|c|c|c|}
\hline Variable & B & SE & $\beta$ & $t$ & $\mathrm{R}^{2}$ & $\mathrm{~F}$ \\
\hline \multicolumn{7}{|c|}{ Consumption $-\Delta$ positive emotions } \\
\hline Constant & -0.64 & 1.30 & & -0.49 & & \\
\hline$\Delta$ Positive emotions & 0.45 & 0.21 & -0.19 & $2.14^{*}$ & 0.04 & $4.57^{*}$ \\
\hline \multicolumn{7}{|c|}{ Consumption $-\Delta$ negative emotions } \\
\hline Constant & -3.86 & 1.05 & & -3.69 & & \\
\hline$\Delta$ Negative emotions & -0.27 & 0.17 & -0.14 & -1.59 & 0.02 & 2.54 \\
\hline
\end{tabular}

Note: ${ }^{* * *} p<0.001,{ }^{* *} p<0.01,{ }^{*} p<0.05$.

Table 2. Regression results of negative emotions on consumptions.

\begin{tabular}{|c|c|c|c|c|c|c|}
\hline Variable & B & SE & $\beta$ & $t$ & $\mathrm{R}^{2}$ & $\mathrm{~F}$ \\
\hline \multicolumn{7}{|c|}{ Negative emotions-consumption sum } \\
\hline Constant & 4.18 & 0.63 & & 6.59 & & \\
\hline Consumption sum & 0.07 & 0.03 & 0.20 & $2.25^{*}$ & 0.04 & $5.07^{*}$ \\
\hline \multicolumn{7}{|l|}{ Consumption—-hedonic consumption } \\
\hline Constant & 1.72 & 0.42 & & 4.11 & & \\
\hline Hedonic consumption & 0.05 & 0.02 & 0.22 & $2.56^{*}$ & 0.05 & $6.54^{*}$ \\
\hline \multicolumn{7}{|c|}{ Consumption-utilitarian consumption } \\
\hline Constant & 2.46 & 0.40 & & 6.21 & & \\
\hline Utilitarian consumption & 0.02 & 0.02 & 0.08 & 0.90 & 0.01 & 0.82 \\
\hline
\end{tabular}


forward ones $(t=3.89, p<0.01 ; t=-5.66, p<0.001)$ and the average of difference is $3.10 \pm 4.37$ and $1.23 \pm$ 1.19. The changes of satisfaction before and after compensation consumption are shown in Figure 4 . The results show that after consumption, participants' positive emotions and satisfaction were improved and negative emotions were decreased.

Besides, consumption sum, including hedonic consumption and utilitarian consumption, has a positive effect on positive emotions and it explains $21 \%$ of the difference. It negatively affects negative emotions and explains $18 \%$ of the difference. In other words, consumption makes sad participants feel more positively and less negatively. The regression results of consumption on the change of positive emotions and negative emotions are shown in Table 3.

Furthermore, negative emotions positively influenced participants' consumption sum and it explains $16 \%$ of the difference. Negative emotions positively influenced participants' hedonic consumption and it explains $18 \%$ of the difference, while it doesn't have an effect on utilitarian consumption. It means that negative emotions would increase consumption, especially hedonic consumption. The regression results of consumption on consumption sum, hedonic consumption and utilitarian consumption are shown in Table 4.

\section{General Discussion}

In present study, we used two different priming method including text and video to evoke participants' sadness. We found that no matter primed by text or video, sad participants would make consumption and sadness and consumption sum is positively related. Due to the results, negative emotions positively affect participants' hedonic consumption and have no significant effect on utilitarian consumption. Compared with the emotions before and after consumption, we discovered that backward negative emotion is lower than forward ones and positive emotions is higher than forward ones. Besides, consumption sum positively influence positive emotions. In study 1 , consumption sum didn't significantly affect negative emotions but in study 2 , the effect is negative. The reason why there's difference between study 1 and study 2 maybe the different priming method. Future study could add field experiment to make sure the exact effect consumption on negative emotions.

Table 3. Regression results of negative emotions on consumption sum, hedonic consumption and utilitarian consumption.

\begin{tabular}{ccccccc}
\hline Variable & B & SE & $\beta$ & $t$ & $\mathrm{R}^{2}$ & $\mathrm{~F}$ \\
\hline Consumption $-\Delta$ positive emotions & & & & & & \\
Constant & -2.38 & 4.24 & & -0.56 & & \\
$\Delta$ Positive emotions & 1.79 & 0.66 & 0.46 & $2.73^{*}$ & 0.21 & $7.44^{*}$ \\
Consumption一 $\Delta$ negative emotions & & & & & & \\
$\quad$ Constant & 4.06 & 4.47 & & -0.91 & & \\
$\Delta$ Negative emotions & -1.74 & 0.69 & -0.43 & $-2.51^{*}$ & 0.18 & $6.30^{*}$ \\
\hline
\end{tabular}

Table 4. Regression results of negative emotions on consumptions.

\begin{tabular}{|c|c|c|c|c|c|c|}
\hline Variable & B & SE & $\beta$ & $t$ & $\mathrm{R}^{2}$ & $\mathrm{~F}$ \\
\hline \multicolumn{7}{|l|}{ Negative emotions - consumption sum } \\
\hline Constant & 3.38 & 1.18 & & 2.86 & & \\
\hline Consumption sum & 0.10 & 0.05 & 0.40 & $2.31^{*}$ & 0.16 & $5.35^{*}$ \\
\hline \multicolumn{7}{|l|}{ Consumption—-hedonic consumption } \\
\hline Constant & 0.74 & 1.00 & & 0.74 & & \\
\hline Hedonic consumption & 0.10 & 0.04 & 0.43 & $2.52^{*}$ & 0.18 & $6.33^{*}$ \\
\hline \multicolumn{7}{|c|}{ Consumption-utilitarian consumption } \\
\hline Constant & 2.64 & 0.96 & & 2.75 & & \\
\hline Utilitarian consumption & 0.01 & 0.04 & 0.04 & 0.22 & 0.002 & 0.05 \\
\hline
\end{tabular}




\section{satisfaction}

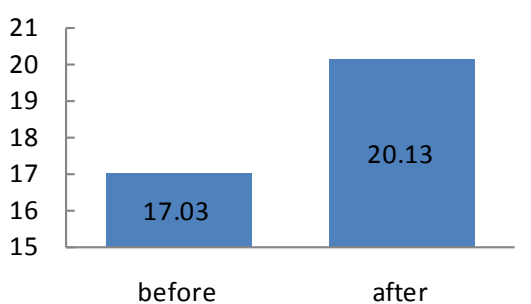

\section{Cantril satisfaction}

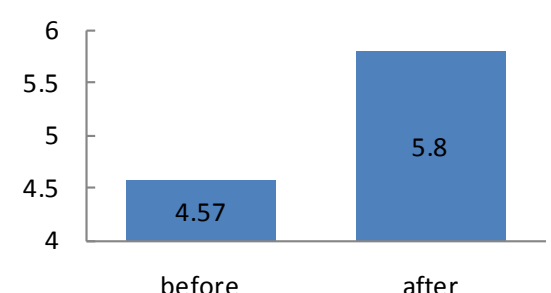

Figure 4. Changes of satisfaction before and after compensation consumption.

\section{Conclusion}

In conclusion, the results show that when people are unhappy, they would release themselves through consumption, especially hedonic consumption. However, this kind of compensary consumption may only improve positive emotions. It's unclear whether consumption has an effect on decreasing negative emotions. Besides, in study 2, we found there's positive effects consumption made on participants' satisfaction. Since subjective wellbeing consists of positive emotions, negative emotions and satisfaction, it means that sad-spending could improve people's subjective well-being. When people are sad, they could go shopping to make them feel happier.

We suggested that sad people could do some hedonic consumption properly. Due to the unclear effect of consumption sum on negative emotions, people would better be rational during consumption. Otherwise, it's also an emergence to find out how long the positive effect of consumption will last. For example, when the time passes, consumption would help consumers' emotional recovery process or bring some other negative emotions like regret and anxiety. If sad-spending only brings short-term benefits, we should remind people to make more rational consumption especially when they are sad. Meanwhile, because of the sad-spending effect, companies could promote the products during some special days, such as Valentine's Day, to stimulus the sadness of people who are still single to consume more.

Future studies could explore the way to decrease sad-spending effect and pay more attentions to moderators. Some scholars proposed that the reason leading to sad-spending is not because consumption could transfer peoples' focus, but due to the feeling of losing control (Atalay \& Meloy, 2011). They found that increasing participants' sense of control would decrease sad-spending (Lerner \& Garg, 2012). What's more, the present study only discusses the change of emotions in short term. Future studies could use longitudinal study in order to explore whether the influence has a difference in long-term study.

\section{References}

Atalay, A. S., \& Meloy, M. G. (2011). Retail Therapy: A Strategic Effort to Improve Mood. Psychology \& Marketing, 28, 638-659. http://dx.doi.org/10.1002/mar.20404

Cryder, C. E., Lerner, J. S., Gross, J. J. et al. (2008). Misery Is Not Miserly Sad and Self-Focused Individuals Spend More. Psychological Science, 19, 525-530. http://dx.doi.org/10.1111/j.1467-9280.2008.02118.x

Garg, N., Wansink, B., \& Inman, J. J. (2007). The Influence of Incidental Affect on Consumers' Food Intake. Journal of Marketing, 71, 194-206. http://dx.doi.org/10.1509/jmkg.71.1.194

Gronmo, S. (1988). Compensatory Consumer Behavior: Elements of a Critical Sociology of Consumption. The Sociology of Consumption, 65-85.

Lerner, J. S., \& Garg, N. (2012). Sadness and Consumption.

Lerner, J. S., \& Keltner, D. (2000). Beyond Valence: Toward a Model of Emotion-Specific Influences on Judgement and Choice. Cognition \& Emotion, 14, 473-493. http://dx.doi.org/10.1080/026999300402763

Li, A. M., \& Li, F. L. (2011). A Review of the Literature of Sad-Spending Effect. Foreign Economies and Management, 28, 638-659.

Manucia, G. K., Baumann, D. J., \& Cialdini, R. B. (1984). Mood Influences on Helping: Direct Effects or Side Effects? Journal of Personality and Social Psychology, 46, 357. http://dx.doi.org/10.1037/0022-3514.46.2.357

Raghunathan, R., \& Corfman, K. P. (2004). Sadness as Pleasure-Seeking Prime and Anxiety as Attentiveness Prime: The "Different Affect-Different Effect” (DADE) Model. Motivation and Emotion, 28, 23-41.

http://dx.doi.org/10.1023/B:MOEM.0000027276.32709.30 
Raghunathan, R., \& Pham, M. T. (1999). All Negative Moods Are Not Equal: Motivational Influences of Anxiety and Sadness on Decision Making. Organizational Behavior and Human Decision Processes, 79, 56-77. http://dx.doi.org/10.1006/obhd.1999.2838

Rucker, D. D., \& Galinsky, A. D. (2013). Compensatory Consumption. The Routledge Companion to Identity and Consumption, 207-215.

Wansink, B., Cheney, M. M., \& Chan, N. (2003). Exploring Comfort Food Preferences across Age and Gender. Physiology \& Behavior, 79, 739-747. http://dx.doi.org/10.1016/S0031-9384(03)00203-8

Woodruffe, H. R. (1997). Compensatory Consumption: Why Women Go Shopping When They're Fed up and Other Stories. Marketing Intelligence \& Planning, 15, 325-334. http://dx.doi.org/10.1108/02634509710193172

Zheng, X. Y., \& Peng, S. Q. (2014). Consumption as Psychological Compensation: A Review of Compensatory Consumption. Advances in Psychological Science, 22, 1-8. 